\title{
Urban Design
}

\section{On the Genesis of Hexagonal Shapes}

\author{
Тӧпи Рии
}

Centre for Regional Science, Umeå University

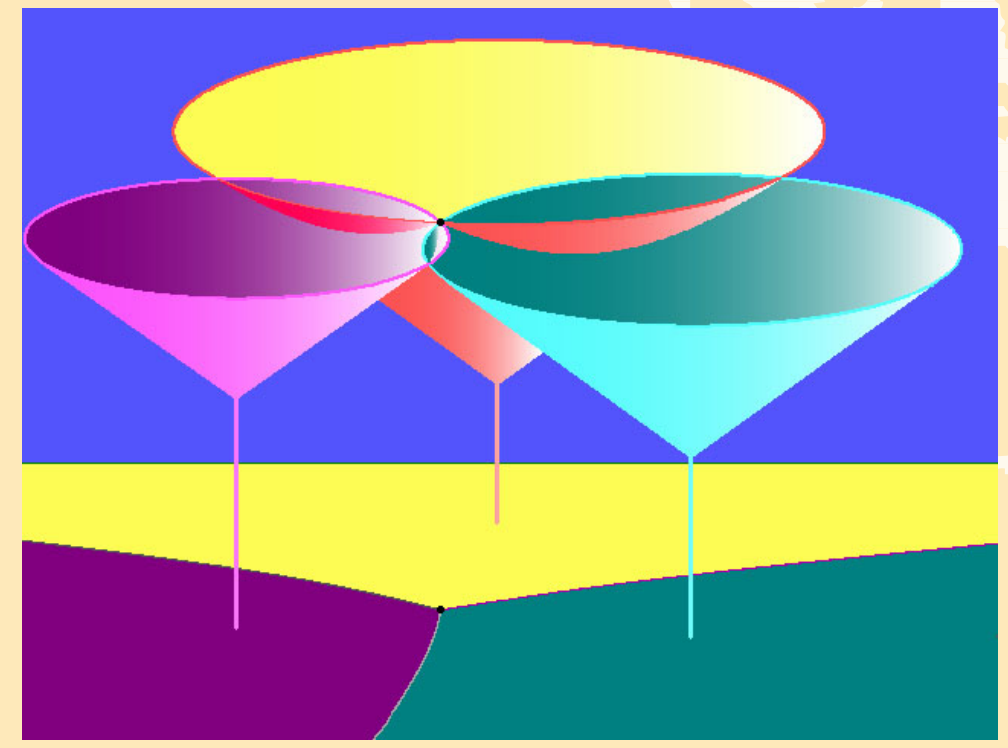





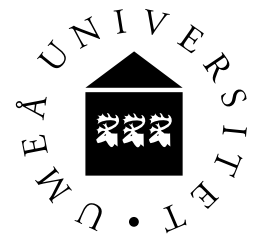

\section{On the Genesis of Hexagonal Shapes}

Тӧпи Рии

Centre for Regional Science, Umeå University

Font: Minion (Adobe)

CERUM Working Paper 73:2004

ISBN 91-7305-621-9

ISSN $1404-5362$

CERUM; Umeå University; SE-90187 Umeå; Sweden

Ph.: +46-90-786.6079 Fax: +46-90-786.5121

Email: regional.science@cerum.umu.se

www.umu.se/cerum 



\title{
On the Genesis of Hexagonal Shapes
}

\author{
Тӧпи Рии \\ CERUM, Umeå University \\ SE-90187 Umeå, Sweden
}

\begin{abstract}
Hexagonal shapes for market areas have been dominant in spatial economics ever since Christaller observed them and Lösch explained their emergence in terms of optimality. It is observed in the following that, though hexagons are best, the differences to for instance squares in terms of efficiency are negligibly small. As the existence of hexagonal shapes - in the space economy, as well as in beehives or other patterns of the physical world cannot be denied -a different cause for their emergence is proposed. Such an explanation is structural stability, which allows three market areas, but not four or six, to come together in each common vertex. The focus is hence the way market areas are organized in space, rather than their shape.
\end{abstract}

\section{Introduction}

Hexagonal shapes for market areas have been generally accepted ever since Christaller (1933) observed them empirically, and Lösch (1954) explained their emergence in terms of their optimality in terms of compactness, hence economy of minimal total transportation cost.

Circular market areas would be the best solution for isolated firms, so the famous reasoning goes, but in aggregate circles cannot pave the plane or any portion of it. There would result overlaps or empty interstices. When pushed together, deformable circles would change their shapes to polygons. Obviously, there cannot be any concave section of the common boundaries. Any consumers located in the area enclosed by a concave boundary section and its tangent, could be supplied at a lower transportation cost by the firm inside the boundary rather than by the competitor. Hence, if exclusively convex areas meet, the boundaries must be made up of straight line segments. Supposing further that the firms are identical, and hence have market areas of equal size, we are left with a choice among the three regular tessellations by equilateral triangles, squares, or regular hexagons, as well known from geometry.

A hexagon has 120 degree angles, so three of them can come together in each corner, making the total of 360. Likewise, four squares with 90 degree angles, or six triangles with 60 degree angles again make up 360. But this exhausts the possibilities. The pentagon will not do, because three of their 108 degree angles only make 324 degrees, so the plane has to be warped to fit three pentagons. Twelve such pentagons actually make up a regular closed surface in three dimensions, and polygons with more corners than six cannot even be fitted on a curved surface. All this was known to Kepler, and, as for the plane, even to Greek antiquity. See Coxeter (1969) and Fejes Tóth (1964) for more detail.

Once we have this choice among the three tessellations, it is easy to show that the hexagon is more compact and more economical than the square, which in its turn is better than the triangle. This is easily acceptable for intuition, because, the hexagon comes closer to the ideal circular shape than the square and the triangle. Of course, an octagon would be even better, but, unfortunately, as we know, it is not admitted as a candidate. 
We have to be more explicit as to what compactness means. In the traditional context of the isoperimetric problem, it means maximum area enclosed by a boundary of given length, or minimum boundary length that encloses a given area size. According to legend, Queen Dido of Carthage, when defeated, was offered as much land as could be covered by the hide of an ass. Cunningly, she cut it in as a thin a thread as possible, and laid it out in the shape of a circle. If we had plenty of Didos, competing for space, they would be squeezed together in hexagons. Apart from legend, medieval cities, surrounded by defence walls, often took a circular shape.

Of course, the relation of boundary length to area enclosed is not the same as the relation of transportation cost to area. We have to make this explicit, and, even if the result often is the same for compactness in terms of minimal boundary length and minimal transportation cost, there are differences. In particular two important issues are involved

i) As soon as we talk of transportation cost in two dimensions, we have to specify which kind of transportation metric we assume. Given a suitable Manhattan metric, the square is even more economical than the circle, as we will see below.

ii) Even assuming the Euclidean metric, which Lösch took for granted, the actual advantage of a hexagon over a square is much smaller in terms of transportation cost (about 1.4 percent saving), than in terms of boundary length (about 7.8 percent saving), which is remarkably small already.

In the sequel we will argue that the actual differences in terms of compactness are so small that it is questionable whether hexagons, when they turn up in the real world, should be attributed to optimality. As a matter of fact they turn up with surprising frequency: See Weyl (1951), Tromba (1985), and Ball (1999).

The most well known everyday experience is the hive of the honeybee, whose cells are hexagonal in crossection. Darwin attributed this to a "wonderful instinct" which was the ultimate evidence for his evolution theory, as it even selected those bees who could best "economize with labour and wax" as those fittest to survive. From biology we also know of the radiolarians (Aulonia Hexagona), tiny spherical organisms whose silicon skeletons are made of hexagonal cells, as illustrated by d'Arcy Wentworth Thompson (1961) in his beautiful book.

From physics we know of Bénard's famous experiment, where a shallow viscous liquid in a cylinder is heated from below, and organizes into hexagonal convection cells, where the liquid rises in the centre of each cell and falls at its boundary. Sometimes atmosphere works as a Bénard liquid, and hexagonal imprint of the winds have been photographed in desert sand. And, from chemistry, similar structures in diffusion have been reported.

The interesting fact is that most of these cases of self organization are in conflict with the natural boundary conditions. A rectangular frame of the kind we know from beehives could accommodate squares only, but not hexagons. There are bound to arise deformed cells along the entire boundary. The same is true about Bénard convection - we cannot cover a circle with hexagons alone.

The case of the radiolarian is even more intriguing: we can build a tetrahedron, or an octahedron, from four or eight triangles, a cube from six squares, and, as we saw, a dodecahedron from twelve pentagons, but we cannot make any closed surface from hexagons alone!

Not even if we deform the faces, so that they no longer fall flat in the plane, and just keep the numbers of faces $(F)$, edges $(E)$, and vertices $(V)$, can we achieve this, because the 
combination of these latter numbers results in the wrong Euler-Poincaré index

$$
V+F-E
$$

For each genus of surface it is a given number. For a surface topologically equivalent to the plane it is 1 , as we can verify for the hexagon $(6+1-6=1)$, or any number of them. Add, for instance two more hexagons that meet in a point. We have 3 faces, 15 edges (18-3, three being shared), and 13 vertices (18-5, three being shared by two and one by three), so $13+3-$ 15 , which is still 1 . And so we can continue adding hexagons, without altering the index. If we take any such aggregate of cells drawn on some elastic sheet, and try to wrap it around a sphere, just identifying vertices with vertices and edges with edges, we will not succeed.

Consider in stead the cube: It has 6 square faces, 8 vertices, and 12 edges, so the index is $8+6-12=2$, so this is the Euler-Poincaré index for a simple closed surface topologically equivalent to a sphere. We get the same number with four triangles organized as a tetrahedron $(4+4-6=2)$, twelve pentagons organized as a dodecahedron $(20+12-30=2)$, or any other of the Platonic solids, as they are called, but we cannot obtain index 2 with any aggregate of hexagons. Concerning surface genus and index numbers, see Henle (1979).

It therefore is truly remarkable that hexagons seem to pave the radiolarian, as it for basic mathematical reasons cannot be paved by hexagons, so that it must have some other polygon somewhere to make the index equation possible. For instance, a football is made from alternating hexagonal and pentagonal patches, but the radiolarian is different: It has just hexagons everywhere, there is just a minimum residual number of different patches to provide for the right genus index.

The forces at work must be truly strong to form hexagonal shapes despite adverse boundary conditions. Once we see how small the advantage of hexagons in terms of optimality are the natural question to ask is whether it is likely that hexagons, which undeniably arise, are due to optimality, or if there may be any other forces at work.

An obvious alternative candidate is stability, more precisely qualitative structural stability in the sense of structural robustness in the presence of random changes or slight misspecifications of the model. Indeed, there is not much point in formulating models, whose outcomes are not just slightly changed at such changes or misspecifications, but turn into something completely different. Samuelson (1947) used this idea in formulating his "correspondence principle": An equilibrium would be without interest if it was not stable. As a rule, assuming stability implies a characterization of the structures that are stable, i.e. a gain of information. Similarly, Arnol'd (1983) suggests that, in modelling the physics of the pendulum, account should be taken of friction, no matter whether we knew of its existence as an empirical fact or not, just because the frictionless pendulum is structurally unstable model, whereas the damped pendulum is stable.

Another word for structural stability is transversality. The concept was systematically explored in the development of catastrophe theory. It all boils down to a condition for transverse intersections of manifolds embedded in a surrounding space: If the sum of the dimensions of two intersecting manifolds equals the sum of the dimensions of the intersection manifold and of surrounding space, then the intersection is transverse, otherwise it is not. Thus, two curves (1-dimensional) in a plane (2-dimensional) intersect in a point ( 0 -dimensional, as $1+1=2+0$, but we could hardly fit a third curve to pass the same intersection point, as we would require $1+0=2+$ ? for a transverse intersection. The intersection manifold would need to have negative dimension, and such geometrical objects do not exist. 
Likewise, two surfaces (2-dimensional) in ordinary space (3-dimensional), intersect transversely along a curve (1-dimensional), as $2+2=3+1$. We can also make a third surface intersect this intersection curve in a point, as $2+1=3+0$, but, again, we could not make a fourth surface intersect this point transversely, as we would need $2+0=3+$ ? to be fulfilled.

Hence we see how neatly the transversality principle sums up all that is typical and robust, and discards what is exceptional and occasional. See Poston and Stewart (1978) for detail.

Let us now again consider the hexagonal tessellation. As we already noted, the tessellation has a property apart from the cells having six edges and six vertices. There are also exactly three cells meeting in each vertex. If the tessellation were square, four cells would meet in each vertex. Now, the market boundaries are formed where the delivery prices accrued with transportation costs of different suppliers break even. Such delivery prices can be considered as surfaces over geographical space, and hence are two dimensional objects that naturally live in three-space. Two such surfaces meet in curves (market boundaries), and three meet at points. But, a fourth delivery price surface could not be fitted to pass this point. Hence, three market areas meet transversely, whereas four do not. The case is even worse with the triangular tessellation, as six areas would have to meet in the vertices.

If we consider market areas of equal size and regular tessellations, then the reverse of three cells meeting at the vertices is the hexagonal shape of the cells. Therefore, structural stability, or transversality, provides a perfect alternative explanation for the hexagonal shapes.

We could easily reconsider Darwin's case. A multitude of bees are building at the same time, pushing against the walls while making cells of their own size, and the joint action produces a shape which is robust. The hexagonal is, but, if the bees had an instinct to build cells of a square crossection, then the slightest careless move by a bee would deform the configuration. Therefore, no recourse to conscious plans or selection of economic instincts is needed. The cells are hexagonal, just because this configuration is robust.

As a further example, take a look at an atlas of countries with national boundaries: We always see three countries coming together in one point, never four or more. The only exception is the case of states in federations, where the borders were drawn by pen and ruler in the hands of some administrator, but it would not be robust to perturbations due to wars, negotiations, and peace treaties. Of course, countries are of different size and power, and therefore we do not see just hexagonal shapes, even topologically. But, given homogeneity and equal size, the reverse of the meeting of three countries would again be hexagons.

This duality between shape and incidence is emphasized by Shäfli's symbols for polygonal tessellations $\{p, q\}$, where $p$ denotes the number of corners in the polygon, and $q$ denotes the number of faces that meet in a corner. As

$$
(p-2)(q-2)=4
$$

in the plane, there are just the three possibilities $\{3,6\},\{4,4\}$, and $\{6,3\}$.

\section{Measures of Economy and Compactness}

As stated above, there are different measures for how compact or economical a certain polygonal shape is. Darwin was concerned with the length of boundary for a cell of given 


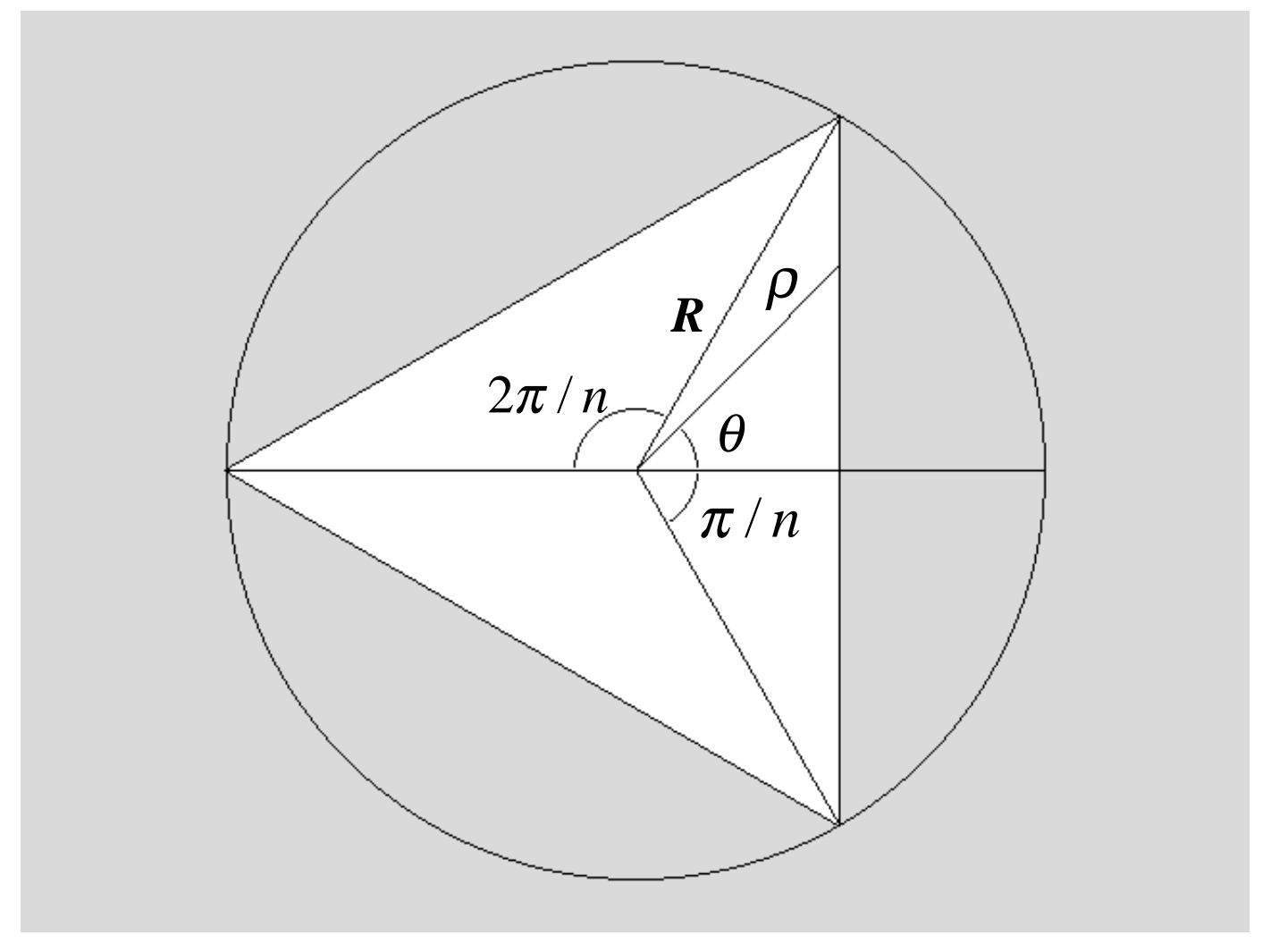

Figure 1. Illustration to the calculation of side length, area, and transportation volume for a polygon.

area content, i.e., with the classical isoperimetric problem. Lösch focused upon total distance from the centre to all the different points of the polygon, or rather again total distance from the respective centres for an aggregate of cells. These measures are, of course, different, though they result in the same conclusion that the hexagon is better than the square, and the square better than the triangle. Though both Darwin and Lösch were concerned with cell aggregates, it is easiest to deal with the measures for an individual cell.

To save labour, we can derive the formulas for a general $n$-gon in one step. Suppose the radius of the circle inscribing the polygon is denoted $R$. Obviously, we can derive all the measures we want by taking one of the identical triangular slices with the centre angle $2 \pi / n$, and then multiply the measures by $n$. See Fig. 1 .

Or, we can do even better: These isosceles triangles have a symmetry axis, so we need only take one half of these, with the central angle $\pi / n$, and finally multiply the measures by $2 n$. As the triangle has one right angle, we right away get the contribution to the perimeter as $R \sin \frac{\pi}{n}$, and the contribution to the area as $\frac{1}{2} R^{2} \sin \frac{\pi}{n} \cos \frac{\pi}{n}$. Multiplying by $2 n$, we get:

$$
L=2 R n \sin \frac{\pi}{n}
$$


and

$$
A=R^{2} n \sin \frac{\pi}{n} \cos \frac{\pi}{n}
$$

where $L$ alludes to length (or linear) and $A$ alludes to area. Let us check what happens when we let $n \rightarrow \infty$. We then have $\lim _{n \rightarrow \infty}\left(n \sin \frac{\pi}{n}\right)=\pi$ and further $\lim _{n \rightarrow \infty}\left(n \sin \frac{\pi}{n} \cos \frac{\pi}{n}\right)=\pi$, so $L=2 \pi R$ and $A=\pi R^{2}$, which are the familiar formulas for the perimeter and the area of a circle, i.e. a polygon with infinitely many sides.

It is slightly more tricky to get total distance from the centre, located at the central angle. We need to integrate:

$$
V=2 n \int_{0}^{\frac{\pi}{n}} \int_{0}^{R \frac{\cos (\pi / n)}{\cos \theta}} r^{2} d r d \theta=2 n R^{3} \cos ^{3} \frac{\pi}{n} \int_{0}^{\frac{\pi}{n}} \frac{d \theta}{\cos ^{3} \theta}
$$

A word of explanation may be needed. We assume an Euclidean distance metric, so the integrand $r$ is the straight line distance from the centre. The second power comes from the change to polar coordinates $d y d x=r d \theta d r$. If we denote the length from the centre in direction $\theta$ by $\rho$, then we have $\rho \cos \theta=R \cos \frac{\pi}{n}$, so, solving for $\rho$, gives us the upper bound for the inner integration.

The expression has a closed form solution:

$$
V=n \frac{R^{3}}{3}\left(\cos \frac{\pi}{n} \sin \frac{\pi}{n}+\cos ^{3} \frac{\pi}{n} \ln \tan \left(\frac{\pi}{4}+\frac{\pi}{2 n}\right)\right)
$$

We understand why $V$ for transportation distance alludes to volume, as it is proportional to the cube of the radius, quite as the area $A$ was proportionate to the square, and the length $L$ just proportional. Geometrically $V$ indeed is a volume: If we erect a right prism of unit height on the polygon, and circumscribe a cone on the same polygonal base, turning it upside down with its centre at the centre of the polygon, then $V$ is the volume of the prism that lies under the inverted cone. See Fig. 2.

It might be tempting to proceed right away to comparing the $L$ :s for the isoperimetric problems, and the $V:$ s for transportation, but the outcome would be misleading. First, we have to calculate $R$ for each polygon so as to make the area unitary. Otherwise boundary length or transportation distance would just be larger for a larger area. Obviously we hence cannot choose the same radius for all polygons. From the expression for $A$, we get:

$$
R=\frac{1}{\sqrt{n \sin \frac{\pi}{n} \cos \frac{\pi}{n}}}
$$




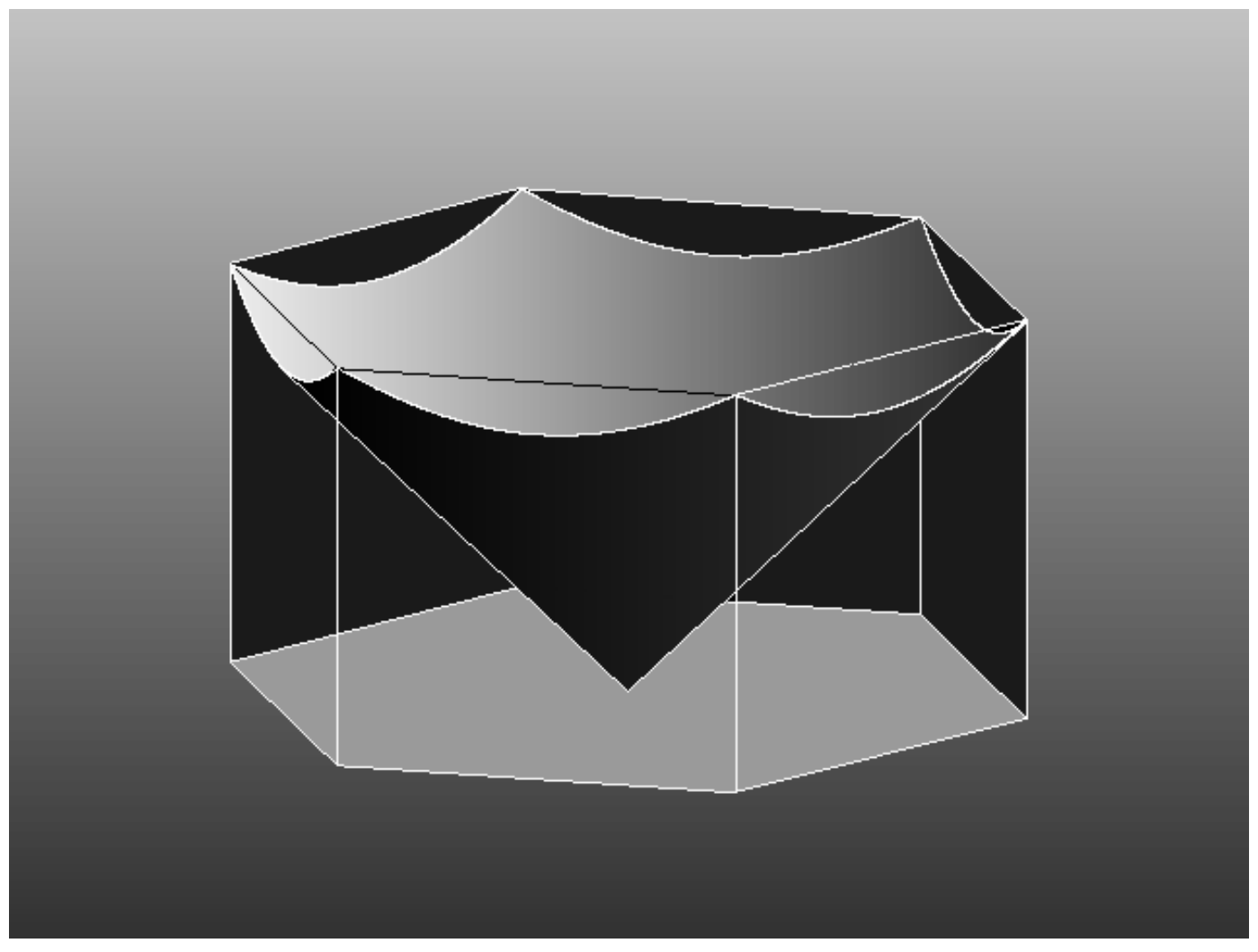

Figure 2. Transportation distance a the volume of a prism under an inverted cone.

as the radius that makes the area of that particular polygon unitary. It is this expression we have to substitute in the expressions for $L$ and $V$ in order to get the measures we want.

Hence, finally:

$$
L=2 \sqrt{n \tan \frac{\pi}{n}}
$$

and

$$
V=\frac{1}{3} \frac{1}{\sqrt{n \cos \frac{\pi}{n} \sin \frac{\pi}{n}}}\left(1+\cos \frac{\pi}{n} \cot \frac{\pi}{n} \ln \tan \left(\frac{\pi}{4}+\frac{\pi}{2 n}\right)\right)
$$

This expression looks quite messy, but for $n \geq 3$, which is fulfilled when we really deal with a polygon, its graph looks very simple and is a uniformly decreasing function, which goes asymptotically to $\frac{2}{3} / \sqrt{\pi}$ as $n$ goes to infinity. The same is true for the much simpler looking $L$, which goes to the asymptotic value $2 \sqrt{\pi}$.

Below we list the exact expressions and the numerical approximations for the triangle, the square, the hexagon, and, finally, the circle: 


$$
\begin{array}{lrl}
L_{3}=2 \cdot 3^{\frac{3}{4}} \approx 4.5590 & V_{3}=\frac{1}{9} 2^{\frac{1}{4}}\left(2+\frac{1}{\sqrt{3}} \ln (2+\sqrt{2})\right) \approx 0.4036 \\
L_{4}=4 & V_{4}=\frac{1}{6}(\sqrt{2}+\ln (1+\sqrt{2})) \approx 0.3826 \\
L_{6}=2 \cdot 12^{\frac{1}{4}} \approx 3.7224 & V_{6}=\frac{1}{3} 12^{\frac{1}{4}}\left(\frac{1}{3}+\frac{1}{4} \ln (3)\right) \approx 0.3772 \\
L_{\infty}=2 \sqrt{\pi} \approx 3.5449 & V_{\infty}=\frac{2}{3} \frac{1}{\sqrt{\pi}} \approx 0.3761
\end{array}
$$

As we see, both in terms boundary length, and in terms of total distance, it is true that the circular shape is the most economical, and that, among the polygonal shapes in a plane tessellation the hexagon is best, the square next best, and the triangle the worst solution.

However, we also see that the differences are very small. In terms of boundary length, the hexagon means a waste of mere 5 percent, and the square of another 7.8 percent. As the ideal circular form is impossible in a tessellation, Darwin's honey bees would save 7.8 percent as compared to other bees that insist on building cells of square crossection.

The case is even less convincing in Lösch's case of minimizing transportation cost. The loss due to the fact that the ideal circular market shape is impossible and the hexagon the best possible is now about 0.3 percent. A transformation from the hexagonal to the square market shape would mean another loss of 1.4 percent. The question to pose, in view of relocation costs and other frictions, is whether the saving of 1.4 percent would provide a convincing explanation for why an actual square tessellation of market areas would be transformed into a hexagonal one.

Too often we just pose questions about optimality, we should also keep in mind how much better the optimal solutions are than other equally possible solutions. It might well be that differences are really small, so that frictions of various kinds prevent the systems from attaining the ultimate optimal state. Or, in case we actually observe the optimal configurations, we should ask if they should not be ascribed to other causes than optimality.

\section{A Case in Solid Geometry}

Solid geometry, which we touched upon in the introduction, is, of course, much more complicated than plane geometry. The regular convex polyhedra, or Platonic solids, three-dimensional equivalents of the regular polygons, which we touched upon, are five: The tetrahedron (with four triangular faces), the cube (with six square faces), the octahedron (with eight triangular faces), the dodecahedron (with twelve pentagonal faces), and the icosahedron (with twenty triangular faces).

The five Platonic solids have fascinated imaginative minds over the ages. Leonardo da Vinci made space models of them, and Kepler, once he was caught by the Copernican heliocentric cosmology, first tried to organize the planetary orbits on spheres which were inscribed in, and themselves inscribed these Platonic polyhedra. See Fig. 3. He was particularly satisfied by the fact that the number of the then known planets agreed with the number 


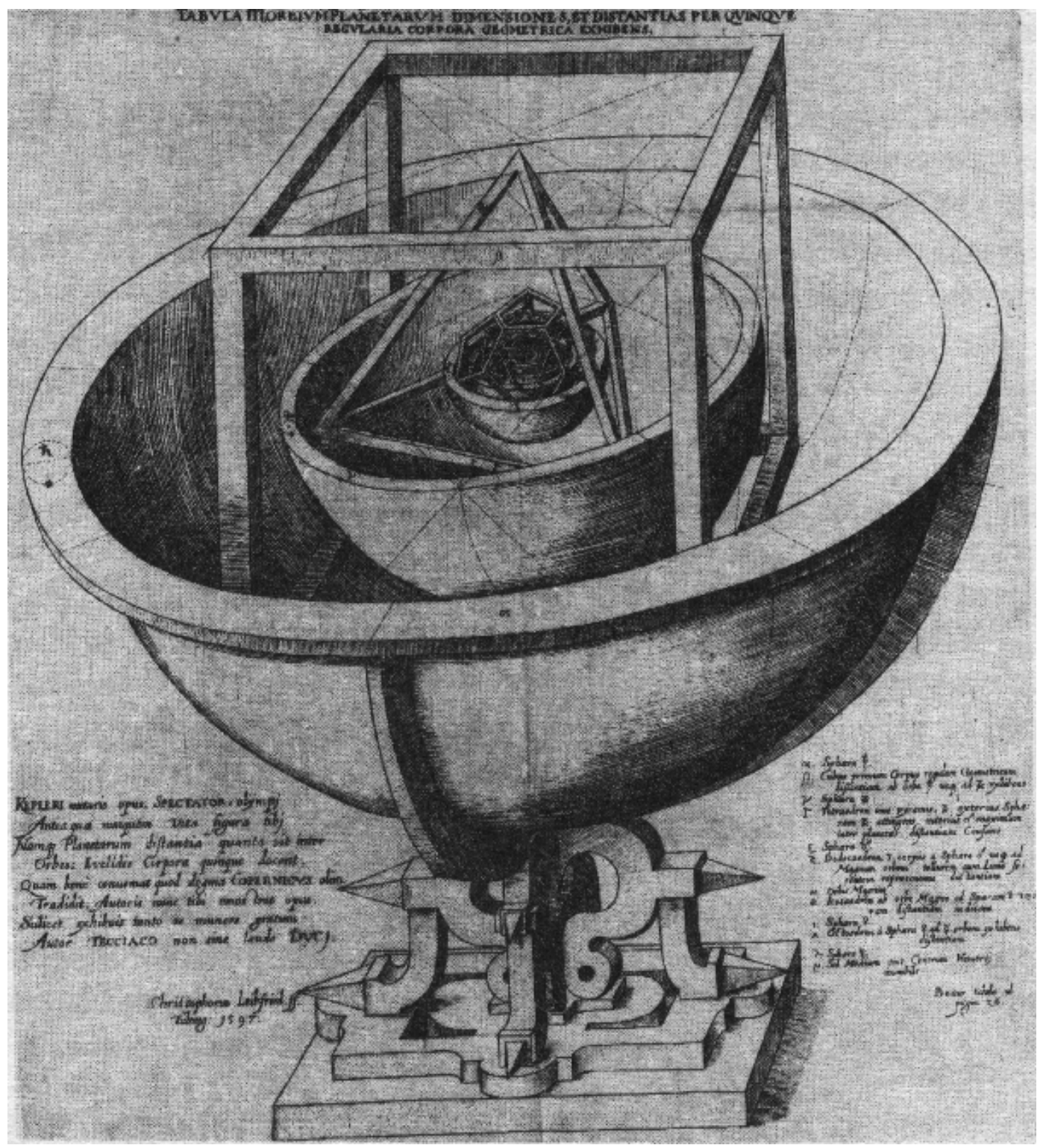

Figure 3. Kepler's first cosmology, with nested spheres and regular polyhedra.

of concentric spheres needed. But this beautiful theory did only fit the orbits for two planets sufficiently well, so Kepler abandoned the theory in favour of the elliptic orbits which made him famous.

Soap bubbles are spherical, shaped by minimizing surface tension, and are the simplest instances of the celebrated Plateau problem. However, none of the space filling convex polyhedra have any optimality properties, such as the hexagon in the plane tessellation has. In this case it would be maximum compactness in terms of least surface area enclosing a given volume. As a matter of fact not all the Platonic solids are even space filling. The cube obviously works, but the icosahedron does not, no matter how we stack them there remain gaps. 
A favourite candidate for such optimality has in stead been the rhombic dodecahedron, which is not a regular solid. It is the shape of the garnet crystal, and has twelve rhombic, not pentagonal faces. It also turns up in beehives, more precisely in the shape the two layers of comb cells that stand back to back in each frame. Darwin could have taken this as additional proof, provided it was certain that the rhombic dodecahedron indeed was the optimal shape in three dimensions. See Fig. 4.

Additional evidence could be ascribed to the following experiment. Soft lead shot, approximately spherical and of equal volume, are loaded in a massive cylinder, and then compressed by a piston (letting gunpowder explode behind the piston). The lead shot are deformed from the spherical shape to the rhombic dodecahedral in each such experiment.

Yet, in his famous Baltimore lectures 1887, Lord Kelvin demonstrated that there exists another space filling solid which has a better economy of surface area to enclosed volume. This is called the tetrakaidekahedron, and is obtained by cutting off all the six corners of an octahedron, so as to produce a solid with alternating squares (at the corners) and hexagons (deformed from the original triangular faces). Kelvin showed how the faces and edges further have to be slightly warped so as to produce the better candidate for optimality. This story is told by Weyl. According to him, nobody knows which is the optimal space filling solid, but there is no doubt that Kelvin's tetrakaidekahedra represent a better solution than the rhombic dodecahedra. However, neither the tetrakaidekhedron nor any other shape than the rhombic dodecahedron ever turns up in experiment. This obviously is a case where frictions impede that the optimal solution is attained, even though the compression is an optimizing procedure.

Though we need not be concerned with the phenomena in tree dimensions here, this case provides an illustration to the weakness of optimization when differences in objective fulfilment are small.

\section{Other Metrics}

Let us, however, consider that we instead of the Euclidean, have a Manhattan type of transportation system, with roads in the diagonal, South-West to North-East, and South-East to North-West directions, infinitely dense, quite as in the case of the Euclidean metric. Suppose further that we have a firm located at the origin.

Then the distance metric from the origin to any point $x, y$ in the plane reads:

$$
|x+y|+|x-y|
$$

Suppose further that the firm has a square market area defined by:

$$
|x+y|+|x-y| \leq 1
$$

This is tilted 45 degrees as compared to the road directions. The boundary of the square is the union of four segments of the lines $x= \pm 0.5, y= \pm 0.5$. As the square has unit sides its area is unity. Suppose the market we consider is part of an infinite tessellation $\left(x_{i}, y_{j}\right)=(i, j)$ with $i, j$ ranging over all integers. Then, assuming that all firms charge the 


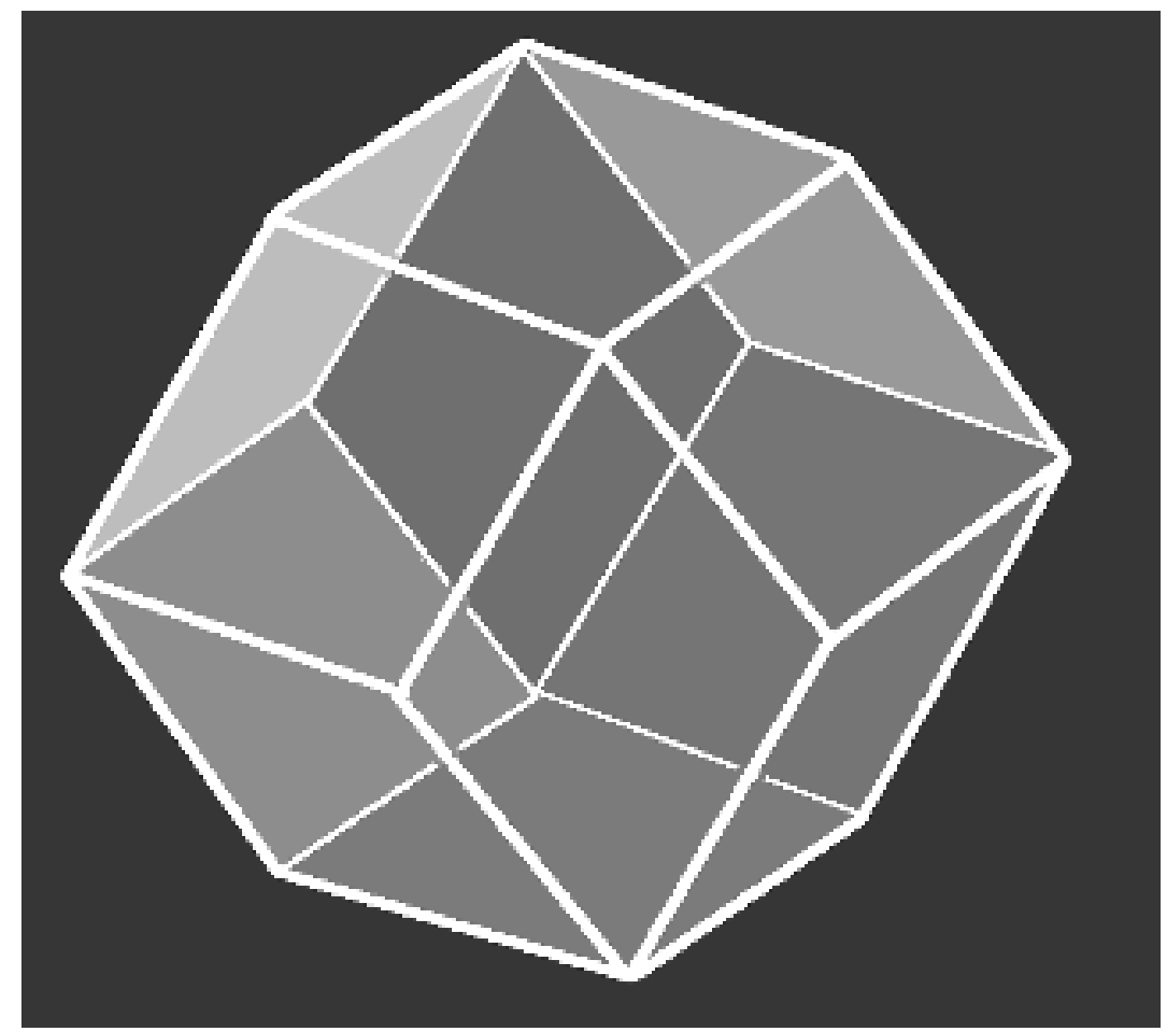

Figure 4. The rhombic dodecahedron.

same mill price and have the same transportation cost as given by our cost metric, the market boundaries are indeed as assumed.

Let us so calculate total transportation cost, for simplicity assuming unit transportation cost, i.e., that the cost has been used as measuring stick to determine the unit distance. It becomes:

$$
\int_{-0.5}^{0.5} \int_{-0.5}^{0.5}(|x+y|+|x-y|) d y d x=\frac{2}{3}
$$

For comparison, let us also calculate the cost for a circular market area. But if we take unit radius we will arrive at the area $\pi$, which is much larger than the unit area for the square. So, to make a fair comparison, we have to choose a radius $1 / \sqrt{\pi}$, which results in unit area. The total transportation cost is then: 


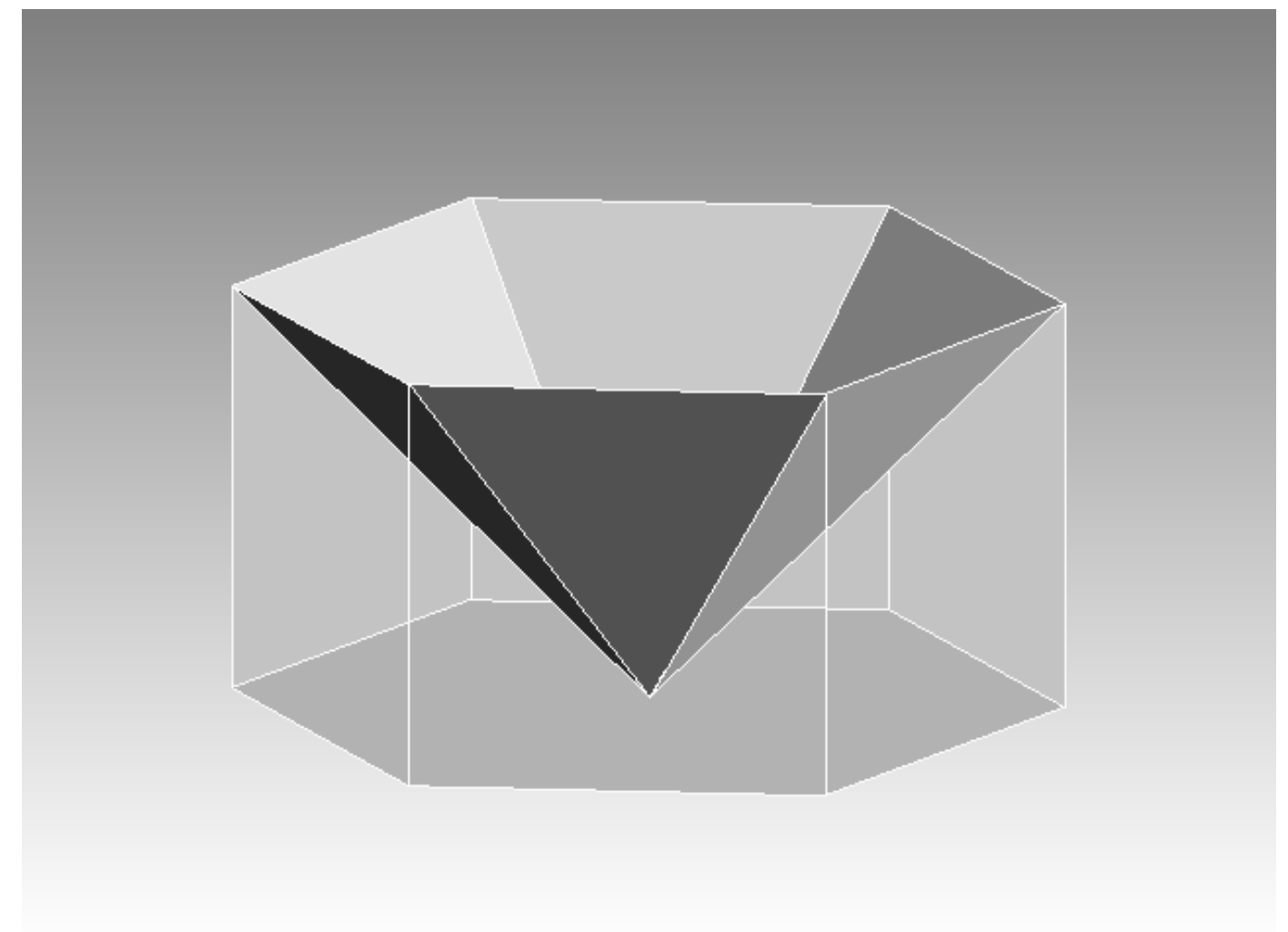

Figure 5. Transportation volume when the heagonal tessellation goes with a corresponding metric..

$$
\int_{0}^{1 / \sqrt{\pi}} \int_{0}^{2 \pi} r^{2}(|\cos \theta+\sin \theta|+|\cos \theta-\sin \theta|) d \theta d r=\frac{8 \sqrt{2}}{3 \pi \sqrt{\pi}}
$$

Note that it was convenient to use polar coordinates $x=r \cos \theta, y=r \sin \theta$. We factored one power of $r$ out from the absolute signs as it is positive in the integration. The second power arises from the conversion to polar coordinates $d y d x=r d \theta d r$.

This expression is slightly higher than for the square, $0.677 \ldots$ as compared to $0.666 \ldots$ Hence, even the circular area is less economical from the view of transportation cost than the square area. Again, differences are small.

Of course, there are many other transportation systems, all leading to different cost metrics, and resulting in different rankings for the shapes of market areas. The Manhattan metric, i.e. $|x|+|y|$, if we align the roads in the West-to-East and South-to-North directions, by rotating them 45 degrees, as compared to the above, and the common Euclidean metric $\sqrt{x^{2}+y^{2}}$, are both examples of the family of Minkowski metrics: 


$$
\left(|x|^{\alpha}+|y|^{\alpha}\right)^{1 / \alpha}
$$

with $\alpha=1$ and $\alpha=2$ respectively. Dual to each transportation system is a system of isodistance loci, concentric squares for the Manhattan, and circles for the Euclidean.

The former is most typical for city regions, along with the ring-radial, which has a more complicated metric, whereas the Euclidean is the traditional distance concept from geometry and used by all the classics. We can also think of roads in three directions inclined at 60 degree angles to each other, as particularly convenient for hexagonal cell aggregates, resulting in the metric:

$$
|x+\sqrt{3} y|+|x-\sqrt{3} y|+|2 x|
$$

Its iso-distance loci are concentric hexagons. This metric would always single out a suitable layout of hexagons as the best tessellation in terms of least transportation cost, as compared to all other polygonal tessellations, and even to the circular cell shape. Without presenting the calculations we just show a picture showing the volume of transportation when such a metric goes with a hexagonal tessellation. See Fig. 5. This is a companion to Fig. 2 where the circular cone is replaced by a hexagonal pyramid, again turned upside down.

So, we see how the optimality depends on the distance metric, and conclude that we, in view of the tiny compactness differences between different cell shapes, should be even more careful when we are not certain about which distance metric to apply, as a different choice reverses the ranking.

\section{Boundary Problems}

When hexagonal cells are enclosed in the rectangular frame of a beehive, or the circular vessel in which Bénard convection is illustrated, or even forced to tile the surface of a spherical radiolarian, the boundary influences the optimality properties of the aggregate. The measure of average boundary per cell depends on how many cells there are, and there is also a waste of space in deformed boundary cells if the shape does not fit exactly in the frame or boundary, as always is the case with hexagons.

As a rule, however, the influence of the boundary decreases the more cells there are in the aggregate. In general we can say that, in the limit, every polygonal tessellation of whatever polygonal shape is just half of that for an isolated polygon of the kind. This is so because, except for the boundary layer, all edges are shared by two cells. The larger the aggregate is, the smaller is the portion of it that belongs to the boundary layer, and in the limit its importance vanishes. Hence, given a sizeable cell aggregate, the measures for boundary length of the individual cells, standardized to unit area are just halved, and hence the optimality comparisons still hold. Probably the numbers of beehive cells in a frame or convection cells in a vessel are large enough to make the influence of the boundary negligible.

More important for us, however, is that the measures of transportation volume are not affected by these boundary matters at all. They are matters of the individual cell and its shape, and independent of how they aggregate together. 


\section{Transversality}

The point of the above reasoning has been to show how weak the argument that hexagonal shapes arise due to their optimality in view of their maximum compactness is. On the other hand, there is no doubt that many hexagonal patterns in fact can be observed in reality. So, we are not denying their existence, but want to find a stronger argument for them.

In the introduction we already indicated one such argument, the structural stability of hexagonal tessellations, as formalized by the principle of transversality.

To make things precise suppose we have a number of firms at different locations $\left(x_{i}, y_{i}\right)$, charging mill prices $p_{i}$. These prices accrue with accumulated transportation costs along the radiating optimal routes from the mill locations, and define local consumers' prices at any point $(x, y)$ of the region considered. The choice of optimal routing may be a complicated problem, quite like the derivation of the resulting local price. See Puu (2003) for examples. But, no matter how complex the transportation system is, for instance including several combined modes, the resulting distance metric (with transportation cost absorbed) between any pair of points is always a unique, well defined, function.

Hence, for the sake of generality, denoting the distance function $d\left(x-x_{i}, y-y_{i}\right)$, we have the local prices:

$$
f_{i}(x, y)=p_{i}+d\left(x-x_{i}, y-y_{i}\right)
$$

If, for instance, we deal with the Euclidean metric, we have

$$
f_{i}(x, y)=p_{i}+\sqrt{\left(x-x_{i}\right)^{2}+\left(y-y_{i}\right)^{2}}
$$

Obviously each local price function

$$
z=f_{i}(x, y)
$$

defines a two dimensional surface in three dimensional $(x, y, z)$-space. Market boundaries are defined through letting two such surfaces intersect. According to the transversality principle, they intersect along a curve, defined by:

$$
z=f_{1}(x, y)=f_{2}(x, y)
$$

For the Euclidean metric:

$$
z=p_{1}+\sqrt{\left(x-x_{1}\right)^{2}+\left(y-y_{1}\right)^{2}}=p_{2}+\sqrt{\left(x-x_{2}\right)^{2}+\left(y-y_{2}\right)^{2}}
$$




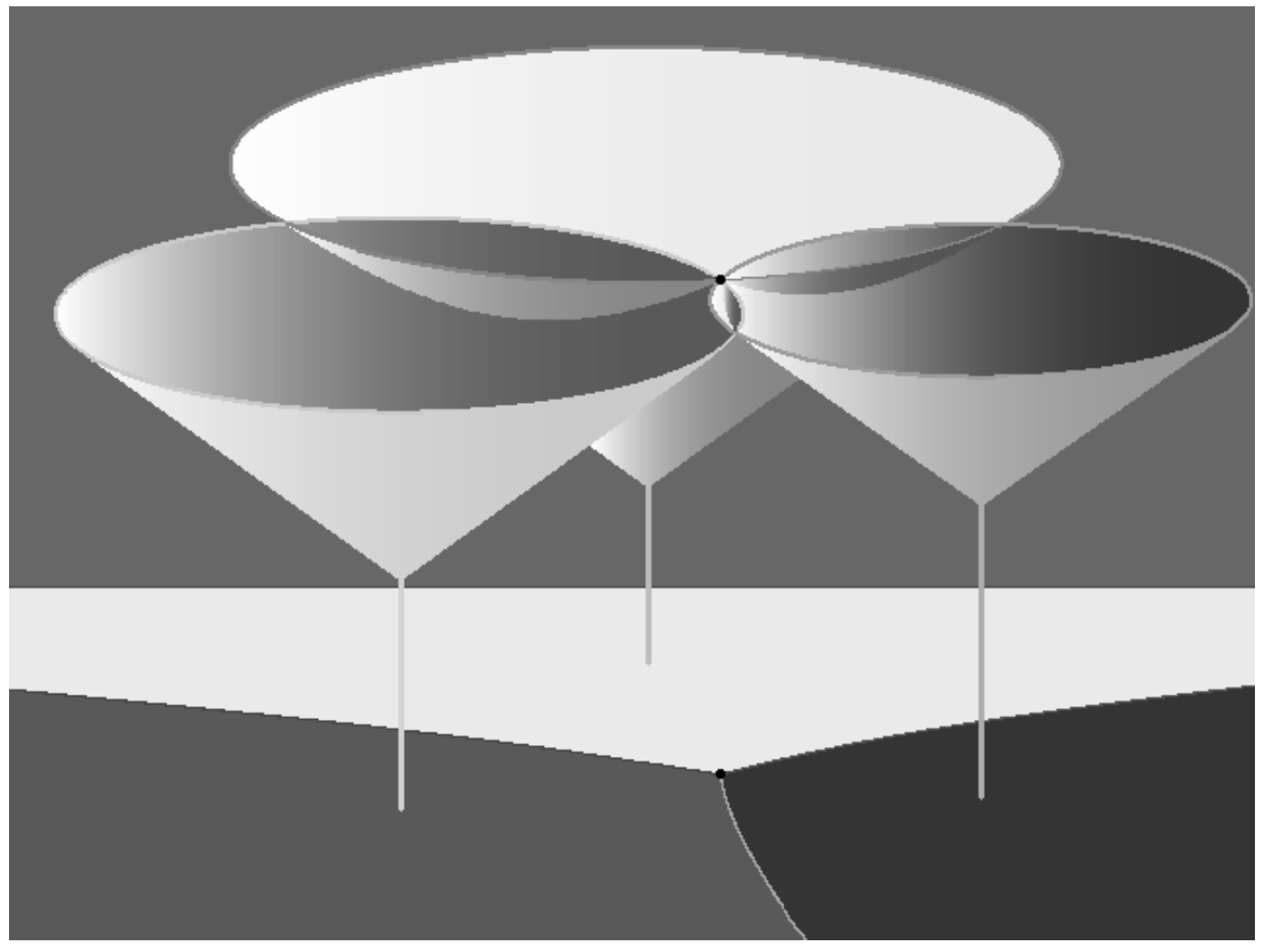

Figure 6. Three intersecting Launhardt funnels, market boundaries, and the three market point.

where the two last equations result in the famous implicit quartic function for the market boundary known from Launhardt's "funnel" construction. The transversality condition is fulfilled, as the dimensions of the two 2-dimensional surfaces $z=f_{1}(x, y)$ and $z=f_{2}(x, y)$, produce the 1-dimensional intersection in 3 -space, so $2+2=3+1$.

Consider now a third firm with its supply price surface $z=f_{3}(x, y)$. Putting:

$$
z=f_{1}(x, y)=f_{2}(x, y)=f_{3}(x, y)
$$

determines a unique point $(\bar{x}, \bar{y}, \bar{z})$. This 0 -dimensional point is the intersection of a new 2dimensional surface and a 1 -dimensional curve in 3 -space, so $2+1=3+0$. Again, we have a transverse intersection.

However, adding a fourth firm, we would require a non-transverse intersection between a 0 -dimensional point $(\bar{x}, \bar{y}, \bar{z})$ and a new 2-dimensional surface $z=f_{4}(x, y)$, which is impossible. It would need a very special configuration of its parameters, mill price $p_{4}$ and location coordinates $\left(x_{4}, y_{4}\right)$ which would be unlikely. The corresponding parameters for the three previous firms were part in the determination of the coordinates of the intersection 

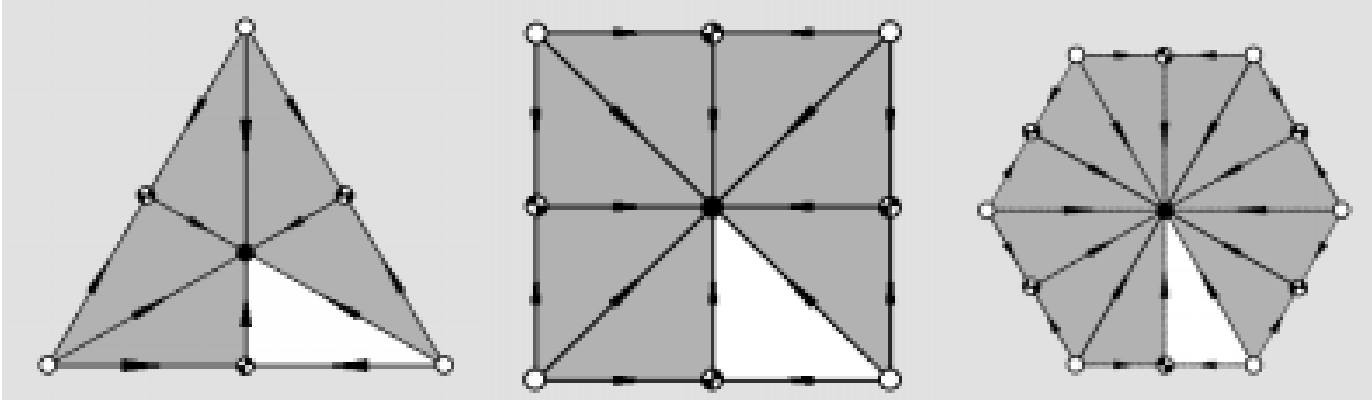

Figure 7. The tessellation elements for flows, basic triangle bright.

point, but it is now given, and the parameters for the fourth firm had no part in its determination, they would just have to be required to fit.

By conclusion, just three firms and no more meet transversely at each vertex. The same holds true all over the tessellation, and produces a set of three-market junctions, which are joined by curve segments which together determine the market areas.

If we add assumptions of convexity, regularity, and equality of market areas, the reverse of this is the hexagonal tessellation. So, it is the only regular tessellation which is robust, and structurally stable. As a conclusion, stability provides a better argument for hexagons than does optimality.

\section{Flows and Stability}

By conclusion, we should add that it matters to what objects in spatial economics we apply structural stability. We applied the considerations to market areas, cell aggregates, assuming a grainy structure of locally monopolistic market areas.

We could, however, also have applied structural stability to flows, of, for instance, traded commodities. The outcome is then quite different. We will outline it briefly in what follows, but the reader can find much more material in Puu (2003).

The facts for structural stability of flows in two dimensions are mainly due to M.M. Peixoto. See Peixoto (1977). The characterization of structurally stable plane flows implies:

i) There are only a finite number of singular (stagnation) points, or limit cycles;

ii) Each of the singularities is of the same type as in linear systems, i.e., a node (stable or unstable), a focus (again stable or unstable), or a saddle point;

iii) There are no so called heteroclinic trajectories connecting saddle points.

Making the further obvious restriction to cases where the flow pattern is an optimizing one, i.e. minimizing transportation cost, eliminates the limit cycles and the foci, and still simplifies the issue: We are left with just nodes, stable and unstable, or sinks and sources, and saddle points, with no trajectories between saddle points.

Now, any flow outside the singular stagnation points (where several trajectories are incident), is topologically equivalent to a set of parallel straight lines, so the singular points provide the organizing element. If we just draw a graph of the set of singular points and 
their connecting trajectories, we find that it can always be triangulated. Further, each such triangle must have exactly one source, one sink, and one saddle point as vertices. We obviously cannot have two sources or two sinks, because on a triangle all vertices are connected. As a trajectory runs from a source to a sink, we could not orient the direction along the side connecting two sinks or two sources. Further, saddle connections were excluded, so we cannot have two saddles either. This leaves us with only one basic triangle, with one source, one sink, and one saddle point. The interior of such a triangle could be filled by other flow lines by free hand. They all issue at the source, pass close by the saddle, and end up at the sink.

To arrive at a regular tessellation element, these elementary triangles have to be reflected in pairs, and arranged cyclically around a singular point of one kind (it makes no difference which). Taking six, we get a triangular element, taking eight, we get a square one, and taking twelve, we get a hexagonal one. These can be multiplied, translated, and again organized in a regular tessellation, this time of the flow pattern. See Fig. 7.

The basic pattern now is square, with equal numbers of sources and sinks, or mixed hexagonal/triangular, with the number of one sort of nodes twice the number of the other. The exclusively hexagonal flow pattern is structurally unstable, because it would have to be organized around monkey saddles, which are about the most unstable feature we could think of.

Though the conclusions are different when transversality is applied to flows than those when they are applied to market areas, we should note that there is no contradiction. The case of market areas with central firms and continuously smeared out consumers is a case of monopolistic competition. Whenever we focus on flow patterns, firms and consumers are equivalent, i.e., both smeared out in space. Hence, the case is one of a competitive market. That conclusions are different for monopoly and competition should be no surprise.

\section{References}

V. I. Arnol'd, 1983, Geometrical Methods in the Theory of Ordinary Differential Equations, (Springer-Verlag)

P. Ball, 1999, The Self-Made Tapestry, (Oxford University Press)

W. Christaller, 1933, Die zentralen Orte in Süddeutschland (Jena)

H. S. M. Coxeter, 1969, Introduction to Geometry, (John Wiley \& Sons, Inc.)

M. Henle, 1979, A Combinatorial Introduction to Topology, (Freeman)

L. Fejes Tóth, 1964, Regular Figures, (Pergamon Press)

A. Lösch, 1954 (translation from the German original 1939, 1943), The Economics of Location

M. M. Peixoto, 1977, "Generic properties of ordinary differential equations", J. Hale (Ed.), Studies in Ordinary Differential Equations, (MAA Studie in Mathematics 14: 54-92)

T. Poston and I. S. Stewart, 1978, Catastrophe Theory and its Applications, (Pitman)

T. Puu, 2001, Mathematical Location and Land Use Theory, (Springer-Verlag)

P. A. Samuelson, 1947, Foundations of Economic Analysis (Harvard University Press)

A. Tromba, 1985, Mathematics and Optimal Form, (Scientific American Books, Inc.)

D. Wentworth Thompson, 1961 (abridged edition from the original 1917, 1942), On Growth and Form, (Cambridge Univesity Press)

H. Weyl, 1952, Symmetry, (Princeton University Press) 


\section{CERUM Working Papers}

Most of these are available at:

www.umu.se/cerum/publikationer/index.html

1. Einar Holm, Ulf Wiberg (Red.) (1995, in Swedish) Samhällseffekter av Umeå universitet

2. Örjan Pettersson, Lars Olof Persson, Ulf Wiberg (1996, in Swedish) Närbilder av västerbottningar - materiella levnadsvillkor och hälsotillstånd $i$ Västerbottens län

3. Jeanette Edblad (1996) The Political Economy of Regional Integration in Developing Countries

4. Lena Sahlin, Lars Westin (1996, in Swedish) Prissättning av subventionerad kultur. Vilka är de internationella erfarenheterna?

5. Lars Westin, Mats Forsman (1997, in Swedish) Regionerna och finansieringen av infrastrukturen: Exemplet Botniabanan

6. Erik Bergkvist, Lars Westin (1997) Estimation of gravity models by oLs estimation, NLs estimation, Poisson, and Neural Network specifications

7. Niklas Nordman (1998) Increasing Returns to Scale and Benefits to Traffic. A Spatial General Equilibrium Analysis in the Case of Two Primary Inputs

8. Lars Westin, Niklas Nordman (1998) The dialogue of universities with their partners: The case of Umeå University, Sweden

9. Robert Sörensson (1998, in Swedish) Systemanalys av godstransporter. Simulering av en uppgraderad Inlandsbana

10. Carina Sundgren (1998, in Swedish) Beräkning av bruttoregionprodukter för Sveriges regioner. En analys av metodvalet och regionindelningens betydelse

11. Erik Sondell (1999, in Swedish) Halvtidsutvärdering av Interreg-projektet Virtual Education Environment MittSkandia

12. Erik Sondell (1999, in Swedish) Det regionala uppdraget: En fjärde uppgift?

13. Örjan Pettersson (1999) Population Changes in Rural Areas in Northern Sweden 1985-1995

14. Robert Pettersson (1999) Foreign Second Home Purchases: The Case of Northern Sweden, 1990-96

15. Patrik Asplund, Niklas Nordman (1999) Attitudes toward the Third Mission: A Selection of Interviews from Seven Universities in Sweden

16. Kent Eliasson, Magnus Johansson, Lars Westin (1999) European Integration: Eastern Europe and the Swedish Regions

17. Janerik Gidlund, Sverker Sörlin, Susanne Gidlund (2000, in Swedish) Ensam hemma. Den norrländska elitens nya syn på regional utveckling

18. Christine Hudson (2000) The University and Regional Reciprocity

19. Linda Helgesson (2000) Why Some Girls Go to School and Others Don't. A study about girls' education on an upper primary level in northern Mozambique

20. Hans Åkerlind (2000, in Swedish) Framtidens stad

21. Göran Aldskogius (2000) Urban Policy in the Structural Policy of the European Union

22. Leif Kåpe (2000, in Swedish) Förändringar i medelstora svenska städer

23. Örjan Petterson, Anna Nordström, Linda Rislund (2000, in Swedish) Utvärdering av LEADER II Stad och Land - Hand i Hand

24. Sören Olsson (2000, in Swedish) Stadens attraktivitet och det offentliga stadslivet

25. Maria Asplund (2000, in Swedish) Elektronik-och dataingenjörsutbildningen $i$ Pajala, Studentperspektivet

26. Lars Marcus (2000) On Architectural Knowledge

27. Henry Etzkowitz, Patrik Aslund, Niklas Nordman (2001) Beyond Humboldt: Emergence of Academic Entrepreneurship in the u.s. and Sweden 
28. Maria Asplund (2001, in Swedish) Om måluppfyllelsen för Umeå universitets elektronik- och dataingenjörsutbildning i Pajala

29. Maria Asplund, Anna Nordström (2001, in Swedish) Utvärdering av SAMs-projektet

30. Eva Bergdahl, Magnus Rönn (2001, in Swedish) Planering för funktionsintegrering - problem och utgångspunkter

31. Maria Asplund (2001, in Swedish) Ex Ante utvärdering av E12 Alliansen

32. Olof Stjernström (red.), Stig-Olof Holm, Johan Håkansson, Urban Lindgren, Håkan Myrlund, Jesper Stage, Kerstin Westin, Lars Westin, Ulf Wiberg (2001, in Swedish) Den hållbara regionen. Om förutsättningar och framtidsmöjligheter för en hållbar samhällsutveckling $i$ Västerbottens län - ett projektförslag

33. Gemma Francès, Ian Layton, Jordi Rosell, Joan Santana, Erik Sondell, Lourdes Viladomiu (2001) The Measurement of On-Farm Diversification

34. Johan Lundberg (2001) On the Determinants of Average Income Growth and Net Migration at the Municipal Level in Sweden

35. Johan Lundberg (2001) A Spatial Interaction of Benefit Spillovers from Locally Provided Public Services

36. Chris Hudson (2001, in Swedish) Regionala partnerskap - ett hot mot eller ett förverkligande av demokrati?

37. Krister Sandberg, Jörgen Johansson (2001) Estimation of Hedonic Prices for Cooperative Flats in the City of Umea with Spatial Autoregressive GMM

38. Elin Lundmark (2002, in Swedish) Fastighetstaxeringsvärdets spridningsmönster i centrala Umeå

39. Ulf Wiberg (2002, in Swedish) Hållbarhet i glesa regionala strukturer-exemplet södra Norrlandskusten

40. Robert Sörensson (2002) Estimation of Interregional Empty Rail Freight Car Flows

41. Emma Lundholm (2002, in Swedish) Den sociala ekonomin i glesa miljöer - en teoretisk diskussion

42. Niklas Bergström (2002, in Swedish) Kontraurbanisering i Umeåregionen

43. Ian Layton, Linda Rislund (2002) Socio-Economic Dimensions of Agricultural Diversification in Västerbotten, Northern Sweden

44. Aurora Pelli (2002) Coping with Innovative On-farm Diversification - a Qualitative Analysis of Farm Household Case Histories from Västerbotten, Sweden

45. Linda Sandberg (2002, in Swedish) Rädslans restriktioner - En studie av kvinnors rädsla $i$ Umeå

46. Martin Paju (2002, in Swedish) Kulturmiliön och den regionala tillväxten Länsantikvariernas syn på de regionala tillväxtavtalen

47. Tönu Puu, Irina Sushko (2002) A Business Cycle Model with Cubic Nonlinearity

48. Patricia Morton (2002) Social Life and Urban Form in a Historical Perspective

49. Marianne Nilson, Sven-Olof Lindquist, Birgitta Elfström, Martin Paju, Lotta Braunerhielm, Jonas Grundberg (2002, in Swedish) Kulturarvet som resurs för regional utveckling

50. Tönu Puu, Anna Norin (2002) Cournot Duopoly when the Competitors Operate under Capacity Constraints

51. Irina Sushko, Tönu Puu, Laura Gardini (2002) Business Cycles: The Hicksian Floor-Roof Model Revisited

52. Johan Lundberg (2002) Using Spatial Econometrics to Analyze Local Growth in Sweden

53. Klas-Göran Sahlén (2002, in Swedish) Hälsa På-projektet: Effekter av förebyggande hembesök hos pigga pensionärer $i$ Nordmaling

54. Maria Fåhraeus, Sofia Lundberg (2002, in Swedish) - Hur gick det till? En utvärdering av Sjuksköterskeprogrammet i Lycksele

55. Maria Fåhraeus, Martin Paju (2002, in Swedish) Utvärdering av sams-projektet etapp II

56. Günter Löffler, Daniel Schrödl (2002) Retail Business in the Functional Region of Umeå 1985-200o

57. Urban Lindgren (2002) Counter-Urban Migration in the Swedish Urban System 
58. Robert Sörensson (2002)

59. Johan Lundberg (2003, in Swedish) Samverkan mellan forskningsinstitutioner och näringsliv. En litteraturöversikt och förslag till framtida forskningsinsatser

6o. Malin Eriksson (2003, in Swedish) Socialt kapital. Teori, begrepp och mätning. En kunskapsöversikt med fokus på folkhälsa

61. Martin Paju (2003, in Swedish) Utvärdering av EU-projektet E12 Alliansens verksamhet under perioden 2000-05-01-2002-07-31

62. Mats-Olov Olsson (2003) Institutional Change in the Russian Forest Sector. Stakeholder Participation in Forest Policy Formulation. The Case of Tomsk

63. Joachim Weißer, Backa Fredrik Brandt (2003, in Swedish) Persontrafik på Botniabanan. En analys av kundpotentialen inom järnvägskorridoren

64. Örjan Pettersson, Pernilla Westerberg (2003, in Swedish) Vägar för samverkan. Storumanföretagares inställning till planeringssamarbete över kommungränsen

65. Tönu Puu, Laura Gardini, Irina Sushko (2003) A Hicksian MultiplierAccelerator Model with Floor Determined by Capital Stock and Tongues of Periodicity in a Family of Two-dimensional Discontinuous Maps of Real Möbius Type

66. Anna Agliari, Laura Gardini, Tönu Puu (2003) Global Bifurcations in Duopoly when the Cournot Point is Destabilized through a Subcritical Neimark Bifurcation

67. Johan Lundberg (2003) Using Spatial Econometrics to Analyze Local Growth in Sweden - Revised and Extended

68. Johan Lundberg (2003) The Regional Growth Pattern in Sweden - a Search for Hot Spots

69. Linda Holmlund (2003, in Swedish) Sjuksköterskor på väg! Regional- och samhällsekonomisk analys av sjuksköterskeutbildningen i Lycksele

70. Anders Lidström (2004) Multi-level Governance - the Case of Umeå

71. Anna Nordström (2004, in Swedish) Receptarier på nätet, hur gick det till? En utvärdering av planeringen och utvecklandet av den nätbaserade receptarieutbildningen vid Umeå universitet

72. Johan Lundberg, Sofia Lundberg och Lars Westin (2004, in Swedish) Hushållens efterfrågan på dagligvaror och val av dagligvarubutik $i$ Umeå kommun

73. Tönu Puu (2004) On the Genesis of Hexagonal Shapes

74. Tönu Puu (2004) Relative Dynamics and the Hicks Trade Cycle Model

75. Malin Eriksson och Göran Lönnberg (2004, in Swedish) En pilostudie om Hälsa och livskvalitet $i$ Storuman - i en jämförelse med Västerbotten $i$ stort 



The Centre for Regional Science at Umeå University, CERUM, initiates and accomplishes research on regional development, carries out multidisciplinary research, and distributes the results to various public organisations. The research projects are pursued in interaction with the numerous scientific disciplines within the regional science field.

The CERUM Working Paper are interim reports presenting work in progress and papers that have been submitted for publication elsewhere. These reports have received only limited review and are primarily used for in-house circulation.

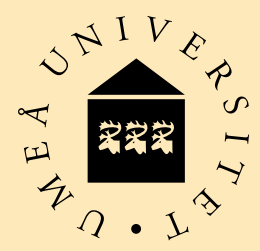

\section{ive CERUM \\ YS Centre for Regional Science}

CERUM; Umeå University; sE-90187 Umeå; Sweden

Ph.: +46-90-786.6079 Fax: +46-90-786.5121

Email: regional.science@cerum.umu.se

www.umu.se/cerum

ISBN 91-7305-621-9

ISSN $1404-5362$ 